\title{
Radiological Estimation of Age from Hand Bone in Sudanese Infants and Toddlers
}

\author{
Mohammed H. Karrar Alsharif1,2, Ali Hassan A. Ali1,3*, Abbas Elbakry A. Elsayed1,4, \\ Abubaker Y. Elamin',5,6, Deya Eldin A. Mohamed 6,7 \\ ${ }^{1}$ Anatomy \& Pediatric Departments, Salman Bin Abdulaziz University, Al-Kharj, KSA \\ ${ }^{2}$ Anatomy Department, Faculty of Medicine University of Science and Technology, Khartoum, Sudan \\ ${ }^{3}$ Anatomy Department, Faculty of Medicine, Al-Azhar University, Cairo, Egypt \\ ${ }^{4}$ Pediatric Department, Faculty of medicine Al-Azhar University, Assiut, Egypt \\ ${ }^{5}$ Emergency Medical Specialty Department, Al-Ghad International Colleges for Applied Medical Sciences, \\ Al Madinah Al Munawarah, KSA \\ ${ }^{6}$ Anatomy Department, School of Medicine, Ahfad University for Women, Omdurman, Sudan \\ ${ }^{7} \mathrm{Al}-$ Ghad International College for Applied Medical Sciences, Dammam, KSA \\ Email: ${ }^{*}$ alihassan3750@yahoo.com, ${ }^{*}$ a.ali@sau.edu.sa
}

Received 12 January 2014; revised 12 February 2014; accepted 19 February 2014

Copyright (C) 2014 by authors and Scientific Research Publishing Inc.

This work is licensed under the Creative Commons Attribution International License (CC BY).

http://creativecommons.org/licenses/by/4.0/

(c) () Open Access

\section{Abstract}

Age determination is one of the most important factors for identification. Unfortunately, births are not recorded regularly in Sudan, especially in rural areas. However, identification of age is very important for a variety of reasons, including identifying legal and criminal responsibility, and for many other social events such as beginning a job, marriage, retirement and joining the army. The study aimed to find the reliability of using international methods to estimate bone age of people through hand bone radiograph in Sudanese people by studying the reliability of using hand bone age "the digital atlas of hand age" which depended on Greulich and Pyle (GP) and Tanner and Whitehouse (TW2/3) methods in Sudanese people in exact group of age, and to compare the hand and wrist bone development between Caucasian and Sudanese people. The study was conducted on 48 samples (26 males and 22 females) from the center of Sudan. The study was made by conventional $X$-Ray taken from Sudanese newborn babies to 2 and 3 years old for males and females respectively. Those images were taken mostly from the emergency and orthopedic outpatient departments. The ages were grouped in the same ways and periods used in the atlas. So the criteria were tested, and the outcomes were compared with international standards in the atlas of hand bone age. There is evidence that skeletal maturation may vary between difference ethnic and socioeconomic groups of children or among children living in various geographical locations. It is found that there is reliability and applicability of using the atlas in Sudanese people with considering that there might be mild variations between Sudanese and Caucasian people's hand and

\footnotetext{
"Corresponding author.
}

How to cite this paper: Alsharif, M.H.K., Ali, A.H.A., Elsayed, A.E.A., Elamin, A.Y. and Mohamed, D.A. (2014) Radiological Estimation of Age from Hand Bone in Sudanese Infants and Toddlers. Open Journal of Internal Medicine, 4, 13-21. 
wrist bone development in which Caucasian people bone growth was earlier than the Sudanese people bones about 1 - 2 months.

\author{
Keywords
}

Hand Bone Age; Infants; Toddlers; X-Ray

\title{
1. Introduction
}

\subsection{General}

Age determination is one of the most important factors for identification. Unfortunately, births are not recorded regularly in Sudan, especially in rural areas. However, identification of age is very important for a variety of reasons, including identifying criminal and legal responsibility, determining the emotional support needed for the victim of a sexual assault, and for many other social events such as marriage, beginning a job, joining the army and retirement. There is evidence that skeletal maturation may vary between difference ethnic and socioeconomic groups of children or among children living in various geographical locations [1].

\subsection{Justifications}

There is much usefulness of bone age in diagnosing hereditary diseases, endocrine disorders [2], growth disorders of children and even genetic disorders [3], also it can be used as an indication of the therapeutic effect of treatment [4], for example:

- For confirming the diagnosis of the normal variants of growth, such as familial short stature (FSS) and constitutional growth delay (CGD), the former is associated with normal skeletal maturation and the latter with delayed bone age.

- For interpreting of hormone blood levels in children at the pubertal age: in particular, the results of laboratory investigations of pituitary-gonadal axis in delayed puberty should be evaluated according to bone age rather than chronological age (for example, we should not expect pubertal values of LH and FSH in a child with bone age less than 12 yrs).

- For diagnosing precocious puberty (differential diagnosis with premature telarche and premature pubarche) or conditions of hyperandrogenism such as congenital adrenal hyperplasia (CAH) characterized by advanced bone age.

- For deciding whether to treat or not children with the above mentioned conditions (precocious puberty and $\mathrm{CAH}$ ), and in monitoring the response of skeletal maturation to the treatment with GnRH analogs and hydrocortisone respectively.

- Postnatally, chronological or true calendar age is calculated from the day of birth. While this may appear to be rather obvious, as with all biological criteria, it is not always accurate.

- Dates of birth are sometimes simply incorrectly recalled or may be falsified for personal reasons.

\section{Materials and Methods}

\subsection{Study Design}

Cross-sectional descriptive study, by conventional Plain radiographs of the hands and wrists were obtained from people that fit the study and the criteria, then we use indicators of skeletal maturity in children and adolescents. The purpose of this section is to describe which bones in the hand and wrist are the most suitable indicators of skeletal maturity during the different phases of postnatal development. In the majority of healthy children, there is an established sequence of ossification for the carpal, metacarpal and phalangeal bones, which is remarkably constant and the same for both sexes. Overall, the first ossification center to appear in hand and wrist radiographs is the capitate, and the last is, most often, the sesamoid of the adductor pollicis of the thumb.

The first epiphyseal center to appear is that of the distal radius, followed by those of the proximal phalanges, the metacarpals, the middle phalanges, the distal phalanges, and, finally, the ulna. There are, however, two main 
exceptions to this sequence: the epiphysis of the distal phalanx of the thumb commonly appears at the same time as the epiphyses of the metacarpals, and the epiphysis of the middle phalanx of the fifth finger is frequently the last to ossify. Since the predictive value of the ossification centers differs and changes during growth, the reviewer should primarily focus on the centers that best characterize skeletal development for the subject's chronological age [5].

\subsection{Study Area}

The data collected from various hospitals in Khartoum city. The data was gathered by random ways, the hospitals included Khartoum Educational Hospital, GafarIbn-Auf Children's Hospital, Om-Durman Educational Hospital, Abo-Seed Educational Hospital, Bahry Educational Hospital, Alsheik Hospital and Ibrahim Malek Hospital.

\subsection{Study Population}

Images were obtained from children who came to the emergency department or orthopedic outpatient department because of suspected trauma. The study group consisted of (48) children (22 girls, 26 boys).

\subsection{Inclusion Criteria}

- From newborn children to 2 years in females and 3 years in males.

- From Sudanese population.

- Children or Patients with traumatic problem but not affecting the study areas.

\subsection{Exclusion Criteria}

- $\quad$ Age before birth \& more than 2 years in females and 3 years in males.

- Patients with any affecting traumas or diseases congenital or acquired.

- Children with poor health care which affect the growth of the bone.

- Very bad quality radiographs.

\subsection{Limitation of the Study}

It was not able to investigate the difference between the variable Sudanese ethnic groups, because our study was performed in the center of Sudan. Socioeconomic status hasn't been controlled in this study, because we did not have reliable data.

\subsection{Data Analysis}

Statistical analysis was performed by using programs SPSS and Excel, after improving the images' resolution by using paint and Microsoft office picture manager programs.

\subsection{Data Collection}

Conventional X-rays have been taken from both hands, the photo included all the regions of the hand in addition to distal end of the radius and ulna.

\subsubsection{Sample Size}

A total of 48 Sudanese infants and toddlers calculated randomly.

\subsubsection{Data Collection Tools and Techniques}

Data tables were formed in order to collect information from the Plain radiographs of the hands and wrists, hand $\mathrm{X}$-rays were taken by using an $\mathrm{X}$-ray generator machine which is a device used to generate $\mathrm{X}$-rays. These devices are commonly used by radiographers to acquire an X-ray image from the object's inside (as in medicine or non-destructive testing) but they are also used in sterilization or fluorescence. To facilitate bone age assessments, It was divided skeletal development into six major categories and highlighted in parentheses the specific ossification centers that are the best predictors of skeletal maturity for each group according to Greulich-Pyle Atlas 
method (GP method [6] and the Tanner Whitehouse 2 Individual Bones method (TW2 method) [7]. This study focuses only on infancy and toddlers groups of age. Here are the groups of age.

1) Infancy (the carpal bones and radial epiphyses).

2) Toddlers (the number of epiphyses visible in the long bones of the hand).

3) Pre-puberty (the size of the phalangeal epiphyses).

4) Early and Mid-puberty (the size of the phalangeal epiphyses).

5) Late Puberty (the degree of epiphyseal fusion).

6) Post-puberty (the degree of epiphyseal fusion of the radius and ulna).

While these divisions are arbitrary, we chose stages that reflect pubertal status, since osseous development conforms better with the degree of sexual development than with the chronologic age. The features that characterize these successive stages of skeletal development are outlined in schematic drawings depicting their appearance as seen in posterior anterior roentgenograms of the hand and wrist [5].

1) Infancy

Females: Birth to 10 months of age

Males: Birth to 14 months of age

All carpal bones and all epiphyses in the phalanges, metacarpals, radius and ulna lack ossification in the fullterm newborn. The ossification centers of the capitate and hamate become apparent at about 3 months of age and remain the only useful observable features for the next six months. At about 10 months of age for girls, and about 1 year and 3 months of age for boys, a small center of ossification in the distal epiphysis of the radius appears. Due to the lack of ossification centers, assessment of skeletal maturity using hand and wrist radiographs during infancy is difficult. Estimates of bone maturation in the first year of life frequently require evaluation of the number, size and configuration of secondary ossification centers in the upper and lower extremities [5].

2) Toddlers

Females: 10 months to 2 years of age

Males: 14 months to 3 years of age

The ossification centers for the epiphyses of all phalanges and metacarpals become recognizable during this stage, usually in the middle finger first, and the fifth finger last. Bone age determinations are primarily based on the assessment of the number of identifiable epiphyseal ossification centers, which generally appear in an orderly characteristic pattern, as follows:

a) Epiphyses of the proximal phalanges.

b) Epiphyses of the metacarpals.

c) Epiphyses of the middle phalanges.

d) Epiphyses of the distal phalanges.

Two common exceptions to this rule are:

a) The early appearance of the ossification center of the distal phalanx of the thumb, which is usually recognizable at 1 year and 3 months in males, and 1 year and six months in females; and

b) The late appearance of the ossification center of the middle phalanx of the fifth finger, which is the last phalangeal epiphysis to appear. The number and degree of maturation of the carpal bones in the wrist are less useful indicators at this stage, as only three or four (capitate, hamate and lunate and, at times, trapezoid) are recognizable [5].

\section{Results}

\subsection{Infancy}

Table 1 shows the numbers, ages and the percentage of the collected data in both genders according to the appearance of the epiphysis in the phalanges, metacarpals and distal ends of radius and ulna which are not seen in this period ${ }^{*}(\mathrm{~m}$ : month).

\subsection{Toddlers}

Table 2 shows the numbers, ages and the percentage of the collected data in both genders according to the appearance of the epiphysis in the phalanges, metacarpals and distal ends of radius and ulna which in this period started to appear in different periods of ages but they showed that there is delay in the beginning ages of this 
Table 1. Numbers, ages and the percentage of the collected data in both genders according to the appearance of the epiphysis in the phalanges, metacarpals and distal ends of radius and ulna which are not seen in this period * (m: month).

\begin{tabular}{|c|c|c|c|c|c|c|c|c|c|c|c|c|}
\hline & \multicolumn{4}{|c|}{ Epiphysis of the phalanges } & \multicolumn{4}{|c|}{ Epiphysis of the metacarpal bones } & \multicolumn{4}{|c|}{ Epiphysis of the radius } \\
\hline & \multicolumn{2}{|c|}{ Not visible } & \multicolumn{2}{|c|}{ Visible } & \multicolumn{2}{|c|}{ Not visible } & \multicolumn{2}{|c|}{ Visible } & \multicolumn{2}{|c|}{ Not visible } & \multicolumn{2}{|c|}{ Visible } \\
\hline Total cases & \multicolumn{4}{|c|}{30} & \multicolumn{4}{|c|}{30} & \multicolumn{4}{|c|}{30} \\
\hline Percent & \multicolumn{2}{|c|}{$100 \%$} & \multicolumn{2}{|c|}{$0.00 \%$} & \multicolumn{2}{|c|}{$100 \%$} & \multicolumn{2}{|c|}{$0.00 \%$} & \multicolumn{2}{|c|}{$100 \%$} & \multicolumn{2}{|c|}{$0.00 \%$} \\
\hline No & Male & Female & Male & Female & Male & Female & Male & Female & Male & Female & Male & Female \\
\hline 1 & $2 \mathrm{~m}$ & $4 \mathrm{~m}$ & & & $2 \mathrm{~m}$ & $4 \mathrm{~m}$ & & & $2 \mathrm{~m}$ & $4 \mathrm{~m}$ & & \\
\hline 2 & $3 \mathrm{~m}$ & $4 \mathrm{~m}$ & & & $3 \mathrm{~m}$ & $4 \mathrm{~m}$ & & & $3 \mathrm{~m}$ & $4 \mathrm{~m}$ & & \\
\hline 3 & $4 \mathrm{~m}$ & $5 \mathrm{~m}$ & & & $4 \mathrm{~m}$ & $5 \mathrm{~m}$ & & & $4 \mathrm{~m}$ & $5 \mathrm{~m}$ & & \\
\hline 4 & $5 \mathrm{~m}$ & $5 \mathrm{~m}$ & & & $5 \mathrm{~m}$ & $5 \mathrm{~m}$ & & & $5 \mathrm{~m}$ & $5 \mathrm{~m}$ & & \\
\hline 5 & $6 \mathrm{~m}$ & $5 \mathrm{~m}$ & & & $6 \mathrm{~m}$ & $5 \mathrm{~m}$ & & & $6 \mathrm{~m}$ & $5 \mathrm{~m}$ & & \\
\hline 6 & $6 \mathrm{~m}$ & $6 \mathrm{~m}$ & & & $6 \mathrm{~m}$ & $6 \mathrm{~m}$ & & & $6 \mathrm{~m}$ & $6 \mathrm{~m}$ & & \\
\hline 7 & $6 \mathrm{~m}$ & $6 \mathrm{~m}$ & & & $6 \mathrm{~m}$ & $6 \mathrm{~m}$ & & & $6 \mathrm{~m}$ & $6 \mathrm{~m}$ & & \\
\hline 8 & $6 \mathrm{~m}$ & $7 \mathrm{~m}$ & & & $6 \mathrm{~m}$ & $7 \mathrm{~m}$ & & & $6 \mathrm{~m}$ & $7 \mathrm{~m}$ & & \\
\hline 9 & $8 \mathrm{~m}$ & $8 \mathrm{~m}$ & & & $8 \mathrm{~m}$ & $8 \mathrm{~m}$ & & & $8 \mathrm{~m}$ & $8 \mathrm{~m}$ & & \\
\hline 10 & $9 \mathrm{~m}$ & $8 \mathrm{~m}$ & & & $9 \mathrm{~m}$ & $8 \mathrm{~m}$ & & & $9 \mathrm{~m}$ & $8 \mathrm{~m}$ & & \\
\hline 11 & $10 \mathrm{~m}$ & $9 \mathrm{~m}$ & & & $10 \mathrm{~m}$ & $9 \mathrm{~m}$ & & & $10 \mathrm{~m}$ & $9 \mathrm{~m}$ & & \\
\hline 12 & $11 \mathrm{~m}$ & $9 \mathrm{~m}$ & & & $11 \mathrm{~m}$ & $9 \mathrm{~m}$ & & & $11 \mathrm{~m}$ & $9 \mathrm{~m}$ & & \\
\hline 13 & $11 \mathrm{~m}$ & $10 \mathrm{~m}$ & & & $11 \mathrm{~m}$ & $10 \mathrm{~m}$ & & & $11 \mathrm{~m}$ & $10 \mathrm{~m}$ & & \\
\hline 14 & $11 \mathrm{~m}$ & & & & $11 \mathrm{~m}$ & & & & $11 \mathrm{~m}$ & & & \\
\hline 15 & $12 \mathrm{~m}$ & & & & $12 \mathrm{~m}$ & & & & $12 \mathrm{~m}$ & & & \\
\hline 16 & $13 \mathrm{~m}$ & & & & $13 \mathrm{~m}$ & & & & $13 \mathrm{~m}$ & & & \\
\hline 17 & $13 \mathrm{~m}$ & & & & $13 \mathrm{~m}$ & & & & $13 \mathrm{~m}$ & & & \\
\hline \multicolumn{13}{|l|}{18} \\
\hline Total & 17 & 13 & 0 & 0 & 17 & 13 & 0 & 0 & 17 & 13 & 0 & 0 \\
\hline Percent & $67.50 \%$ & $32.50 \%$ & $0.00 \%$ & $0.00 \%$ & $67.50 \%$ & $32.50 \%$ & $0.00 \%$ & $0.00 \%$ & $67.50 \%$ & $32.50 \%$ & $0.00 \%$ & $0.00 \%$ \\
\hline
\end{tabular}

group and the exact start is in age two with $100 \%$ percent of the collected data for proximal phalanges \& radius, also in the metacarpals middle and distal phalanges it appeared but with less percent "75\%" in males but in female according to the division of the group it started from age 10 months which could be sometimes appear and sometimes not but for sure they will appear in the first year for the proximal phalanges with some delay to the mid or the end of the first year for the metacarpals, also there is some varies in the middle and distal phalanges which for most tend to appear at the end of the first year, but for the radius it started with the proximal phalanges. And for the ulna it didn't appear in all cases * (m: month, y: year).

Figure 1 shows the differences in the presence of the epiphysis of the proximal phalanges in different ages of this group in both genders.

Figure 2 shows the differences in the presence of the epiphysis of the metacarpal bones in different ages of this group in both genders.

Figure 3 shows the differences in the presence of the epiphysis of the middle phalanges in different ages of this group in both genders.

Figure 4 shows the differences in the presence of the epiphysis of the radius in different ages of this group in both genders.

Figure 5 shows the differences in the presence of the epiphysis of the distal phalanges in different ages of this group in both genders. 
Table 2. The appearance of the epiphysis in the toddlers group.

\begin{tabular}{|c|c|c|c|c|c|c|c|c|c|c|c|c|}
\hline & \multicolumn{4}{|c|}{ Epiphysis of the proximal phalanges } & \multicolumn{4}{|c|}{ Epiphysis of the metacarpal bones } & \multicolumn{4}{|c|}{ Epiphysis of the middle phalanges } \\
\hline & \multicolumn{2}{|c|}{ Recognized } & \multicolumn{2}{|c|}{ Not Recognized } & \multicolumn{2}{|c|}{ Recognized } & \multicolumn{2}{|c|}{ Not Recognized } & \multicolumn{2}{|c|}{ Recognized } & \multicolumn{2}{|c|}{ Not Recognized } \\
\hline total & \multicolumn{4}{|c|}{18} & \multicolumn{4}{|c|}{18} & \multicolumn{4}{|c|}{18} \\
\hline percent & \multicolumn{2}{|c|}{$77.80 \%$} & \multicolumn{2}{|c|}{$12.20 \%$} & \multicolumn{2}{|c|}{$55.50 \%$} & \multicolumn{2}{|c|}{$44.50 \%$} & \multicolumn{2}{|c|}{$55.50 \%$} & \multicolumn{2}{|c|}{$44.50 \%$} \\
\hline No & Male & Female & Male & Female & Male & Female & Male & Female & Male & Female & Male & Female \\
\hline 1 & $19 \mathrm{~m}$ & $1 \mathrm{y}$ & $1.5 \mathrm{y}$ & $10 \mathrm{~m}$ & $2 \mathrm{y}$ & $1 \mathrm{y}$ & $1.5 \mathrm{y}$ & $10 \mathrm{~m}$ & $2 y$ & $1 \mathrm{y}$ & $1.5 \mathrm{y}$ & $10 \mathrm{~m}$ \\
\hline 2 & $2 y$ & $14 \mathrm{~m}$ & $1.5 \mathrm{y}$ & & $2 y$ & $14 \mathrm{~m}$ & $1.5 \mathrm{y}$ & $14 \mathrm{~m}$ & $2 \mathrm{y}$ & $14 \mathrm{~m}$ & $1.5 \mathrm{y}$ & $17 \mathrm{~m}$ \\
\hline 3 & $2 \mathrm{y}$ & $14 \mathrm{~m}$ & $1.5 \mathrm{y}$ & & $2 \mathrm{y}$ & $1.5 \mathrm{y}$ & $1.5 \mathrm{y}$ & $17 \mathrm{~m}$ & $2 \mathrm{y}$ & $14 \mathrm{~m}$ & $1.5 \mathrm{y}$ & $19 \mathrm{~m}$ \\
\hline 4 & $2 \mathrm{y}$ & $1.5 \mathrm{y}$ & & & $3 y$ & $19 \mathrm{~m}$ & $19 \mathrm{~m}$ & & $3 y$ & $1.5 \mathrm{y}$ & $19 \mathrm{~m}$ & \\
\hline 5 & $2 \mathrm{y}$ & $17 \mathrm{~m}$ & & & & $2 \mathrm{y}$ & $2 \mathrm{y}$ & & & $2 \mathrm{y}$ & $2 \mathrm{y}$ & \\
\hline 6 & $3 y$ & $19 \mathrm{~m}$ & & & & $2 \mathrm{y}$ & & & & $2 \mathrm{y}$ & & \\
\hline 7 & & $2 \mathrm{y}$ & & & & & & & & & & \\
\hline 8 & & $2 y$ & & & & & & & & & & \\
\hline total & 6 & 8 & 3 & 1 & 4 & 6 & 5 & 3 & 4 & 6 & 5 & 3 \\
\hline \multirow[t]{3}{*}{ percent } & $33.30 \%$ & $44.40 \%$ & $16.70 \%$ & $5.60 \%$ & $22.20 \%$ & $33.30 \%$ & $27.80 \%$ & $16.70 \%$ & $22.20 \%$ & $33.30 \%$ & $27.80 \%$ & $16.70 \%$ \\
\hline & \multicolumn{4}{|c|}{ Epiphysis of the distal phalanges } & \multicolumn{4}{|c|}{ Epiphysis of the radius } & \multicolumn{4}{|c|}{ Epiphysis of the ulna } \\
\hline & \multicolumn{2}{|c|}{ Recognized } & \multicolumn{2}{|c|}{ Not Recognized } & \multicolumn{2}{|c|}{ Recognized } & \multicolumn{2}{|c|}{ Not Recognized } & \multicolumn{2}{|c|}{ Recognized } & Not $\mathrm{Re}$ & ognized \\
\hline total & & & & & & & 18 & & & & 18 & \\
\hline percent & 42. & $0 \%$ & & $10 \%$ & & $.33 \%$ & & $6.67 \%$ & & $00 \%$ & & $\%$ \\
\hline No & Male & Female & Male & Female & Male & Female & Male & Female & Male & Female & Male & Female \\
\hline 1 & $2 \mathrm{y}$ & $2 \mathrm{y}$ & $19 \mathrm{~m}$ & $1 \mathrm{y}$ & $1.5 \mathrm{y}$ & $10 \mathrm{~m}$ & $1.5 \mathrm{y}$ & $1 \mathrm{y}$ & & & $1.5 \mathrm{y}$ & $10 \mathrm{~m}$ \\
\hline 2 & $2 \mathrm{y}$ & $2 \mathrm{y}$ & $1.5 \mathrm{y}$ & $14 \mathrm{~m}$ & $1.5 \mathrm{y}$ & $14 \mathrm{~m}$ & $19 \mathrm{~m}$ & & & & $1.5 \mathrm{y}$ & $1 \mathrm{y}$ \\
\hline 3 & $2 \mathrm{y}$ & $10 \mathrm{~m}$ & $1.5 \mathrm{y}$ & $14 \mathrm{~m}$ & $2 \mathrm{y}$ & $14 \mathrm{~m}$ & & & & & $1.5 \mathrm{y}$ & $14 \mathrm{~m}$ \\
\hline 4 & $3 y$ & & $1.5 \mathrm{y}$ & $17 \mathrm{~m}$ & $2 \mathrm{y}$ & $17 \mathrm{~m}$ & & & & & $19 \mathrm{~m}$ & $14 \mathrm{y}$ \\
\hline 5 & & & $2 \mathrm{y}$ & $19 \mathrm{~m}$ & $2 \mathrm{y}$ & $19 \mathrm{~m}$ & & & & & $2 y$ & $19 \mathrm{~m}$ \\
\hline 6 & & & & $2 \mathrm{y}$ & $2 \mathrm{y}$ & $2 \mathrm{y}$ & & & & & $2 y$ & $19 \mathrm{~m}$ \\
\hline 7 & & & & & $3 y$ & $2 y$ & & & & & $2 \mathrm{y}$ & $2 \mathrm{y}$ \\
\hline 8 & & & & & & $2 y$ & & & & & $2 y$ & $2 \mathrm{y}$ \\
\hline & & & & & & & & & & & $3 y$ & $2 \mathrm{y}$ \\
\hline Total & 4 & 3 & 5 & 6 & 7 & 8 & 2 & 1 & 0 & 0 & 9 & 9 \\
\hline percent & $22.20 \%$ & $16.70 \%$ & $27.80 \%$ & $33.30 \%$ & $38.90 \%$ & $44.40 \%$ & $11.10 \%$ & $5.60 \%$ & $0.00 \%$ & $0.00 \%$ & $0.00 \%$ & $0.00 \%$ \\
\hline
\end{tabular}

\section{Discussion}

\subsection{Introductory to the Discussion}

To establish the age of an individual from a bone, or bone element, it is necessary to identify it in one of its three phases of development. First, the time at which the ossification center appears; second, the morphological appearance including the size of the center and finally, where appropriate, the time of fusion of the center with another separate center of ossification.

Because the various bones of the skeleton are very different in function, growth pattern and timescale of development, these three phases will not necessarily apply either to all bony elements, or to all situations that require estimation of age. The three phases will be considered in relation to the source material from which they are derived. 


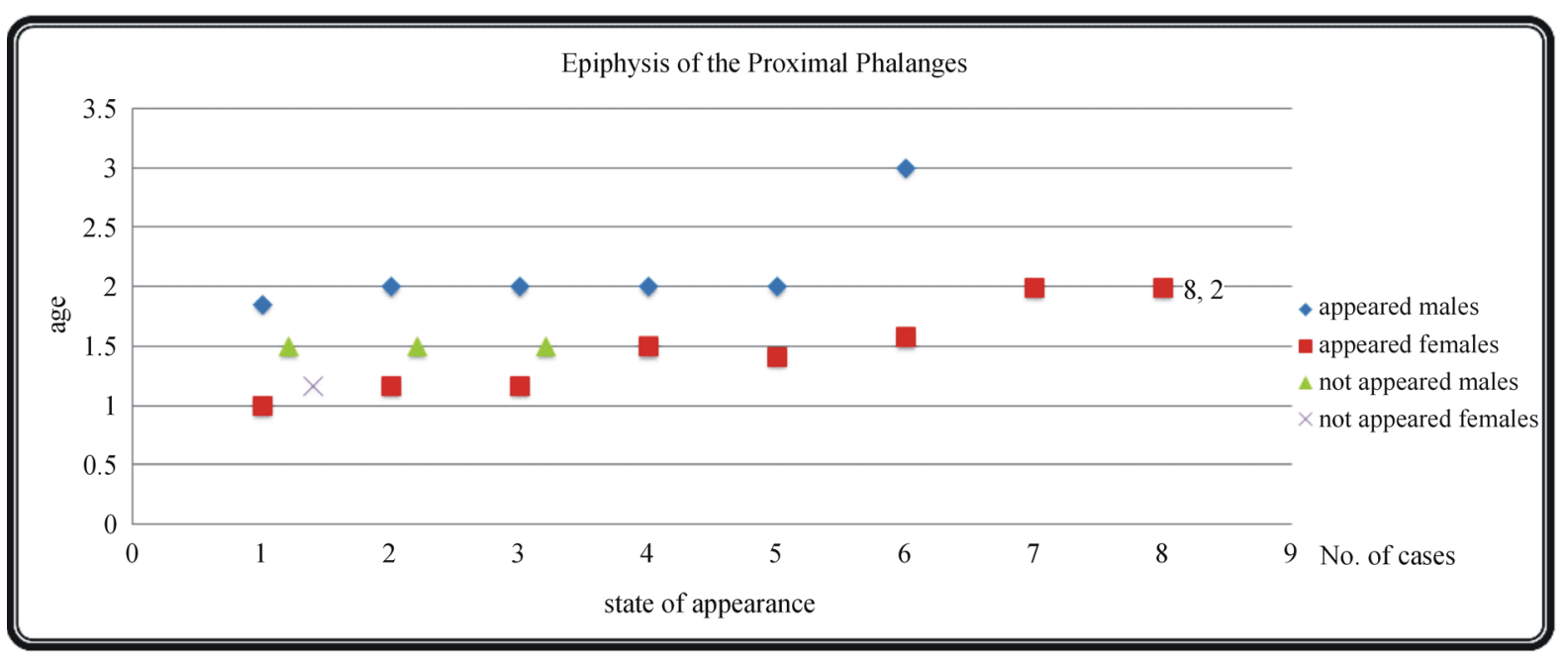

Figure 1. Epiphysis of the proximal phalanges.

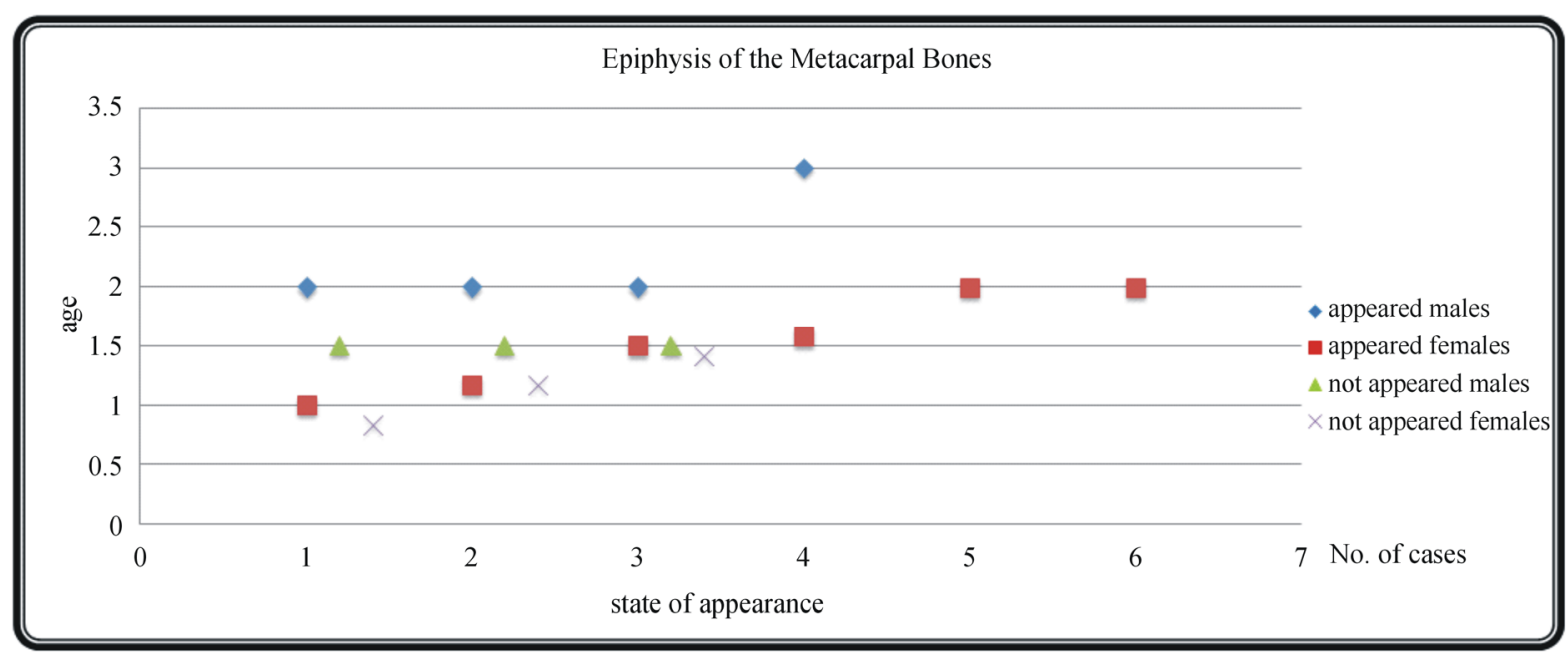

Figure 2. Epiphysis of the metacarpal bones.

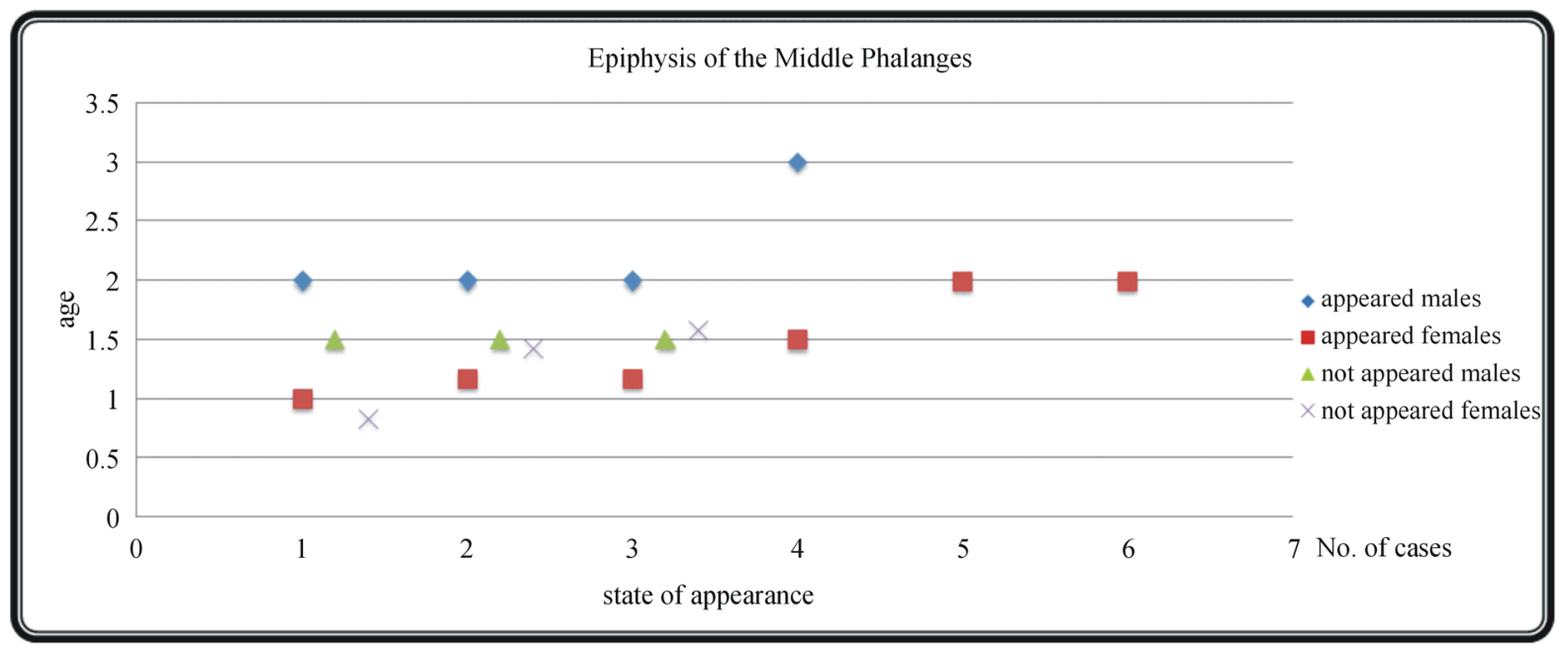

Figure 3. Epiphysis of the middle phalanges. 


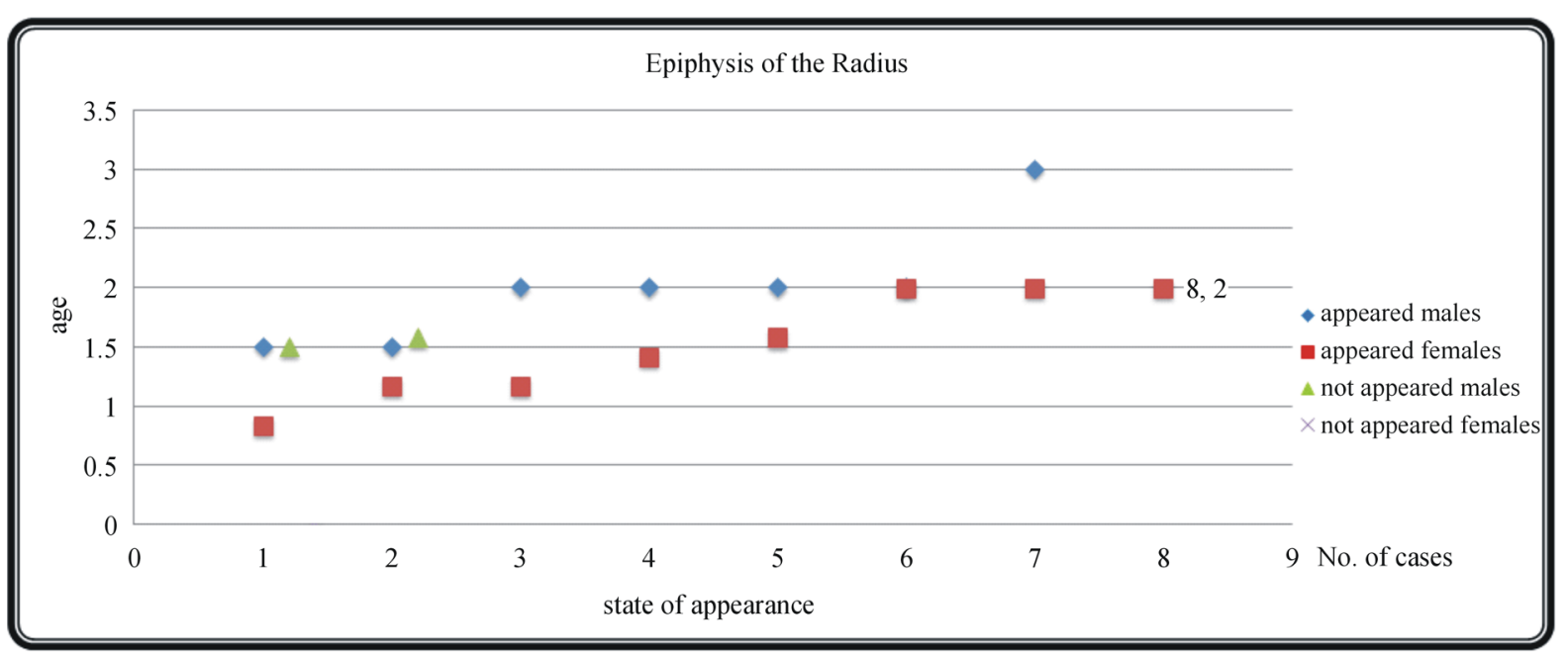

Figure 4. Epiphysis of the radius.

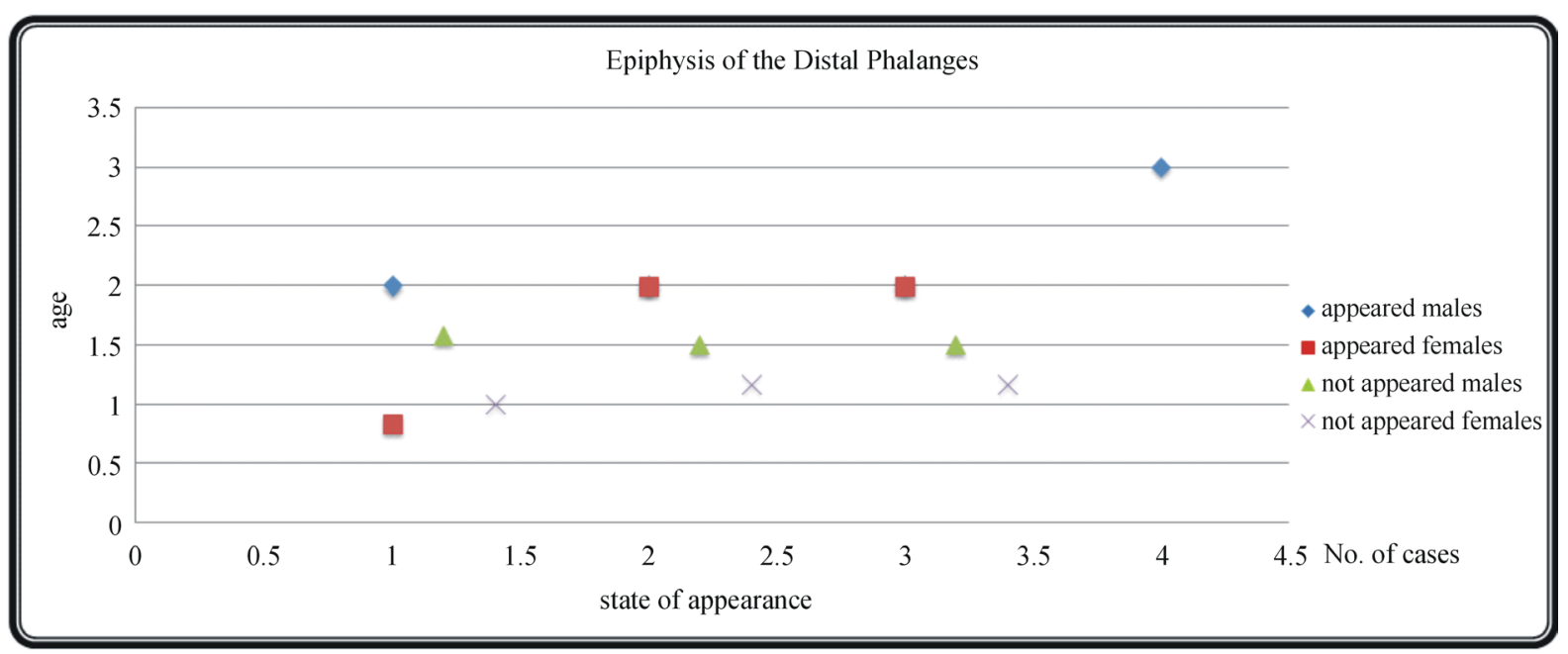

Figure 5. Epiphysis of the distal phalanges.

\subsection{The Ages}

The subjects' ages division for each group was taken by the same way used in hand bone age "digital atlas of skeletal maturity", we tested all the criteria which had been used in measurement of the ages in those groups to find if there is a reliability and compatibility of using this book and the international ways established by Tanner Whitehouse (TW2) and Greulich and Pyle (G\&P) to estimate the age in Sudanese children. We will not forget to say that according to Bull [8] the TW2 method is the more reproducible and more accurate.

\subsection{Groups' Discussion}

\subsubsection{Infancy Period}

We found that all epiphysis of the hand in all data still not appeared. So as mentioned in the atlas there is no difference between the concluded results and the standard of the digital atlas. Adding to this point, it would be better for this period to estimate age using the carpal bones "specially capitate \& hamate which appeared in high percent in the 3rd month in males and 2nd month in females.

\subsubsection{Toddler Period}

The findings show that the epiphysis of the hand bones started to appear as following: 
- Epiphysis of the metacarpal and phalanges

They grow in about $77.80 \%$ in the proximal phalanges and $55.50 \%$ in metacarpal bones and middle phalanges and $42.90 \%$ for distal phalanges. So it would be the best if we use the proximal phalanges because they appeared in this group earlier than the others. but we can use in the same order they appeared in the photos, but also we should keep in mind that some of the collected data may appear in age "2-year for males and 1 year for females" for the epiphysis of the proximal phalanges. So the overall result that we can use the standard in this group without neglecting these points.

- Epiphysis of the radius and ulna

The photos showed that distal end epiphysis' their percent of appearing was about $83.33 \%$ of the collected data for the radius and with no percent was the ulnar epiphysis'.

\section{Conclusion}

The results and the analysis of our study showed that there is reliability and applicability of using Hand Bone Age "digital atlas of skeletal maturity", the standard of which was established by Greulich-Pyle (GP method) and Tanner White House (TW2 method) in Sudanese infancy and toddlers. Without ignoring the exceptions between the Caucasian and Sudanese people, the variation is from 2 to 4 months "i.e. the Caucasian hand and wrist bone growth is earlier". But we might find some exceptional cases that their development might happen earlier, in those cases the reason could be racial, nutritional, environmental or even genetical (multifactorial).

\section{Recommendations}

- We recommend doing researches with taking samples from different centers in the country to cover all races and places.

- Increasing the sample size to cover all the possibilities and to give more accurate results.

- We recommend more comparative studies in hand bone age in Sudanese children to assure our study.

- We recommend making a hand bone age atlas for Sudanese children.

- We recommend making a digital atlas for hand bone age for the comparison instead of the conventional radiographs or the traditional method of comparison.

- We recommend doing researches which explain the causes of the differences between the Sudanese and Occasion children, whether they nutritional, racial, environmental or genetical.

\section{References}

[1] Poznanski, A.K., Garn, S.M., Nagy, J.M. and Gall, J.C. (1972) Metacarpophalangeal Pattern Profiles in the Evaluation of Skeletal Malformation. Radiology, 104, 1-11.

[2] Tanner, J.M., Realy, J. and Goldstein, H. (2001) Assessment of Skeletal Maturity and Prediction of Adult Height (TW3 Method). Harcourt Publishers, New York.

[3] Poznanski, A., Hernandez, R., Guire, K., Bereza, U. and Garn, S. (1978) Carpal Length in Children-A Useful Measurement in the Diagnosis of Rheumatoid Arthritis and Some Concenital Malformation Syndromes. Radiology, 129, 661-668.

[4] Darlin, D. (1979) Radiography of Infants and Children. Harcourt Publishers, New York.

[5] Gilsanz, V. and Ratib, O. (2005) Hand Bone Age, a Digital Atlas of Skeletal Maturity. Springer-Verlag, Berlin, Heidelberg, 1-92.

[6] Greulich, W.W. and Pyle, S.I. (1971) Radiographic Atlas of Skeletal Development of Hand Wrist. Stanford University Press, Palo Alto.

[7] Tanner, J.M., Whitehouse, R.H., Marshall, W.A., Healy, M.R. and Goldstein, H. (1975) Skeletal Maturity and Prediction of Adult Height (TW2 Method). Academic, New York.

[8] Michael, D.J. and Nelson, A.C. (1989) HANDX: A Model-Based System for Automatic Segmentation of Bones from Digital Hand Radiographs. IEEE Transactions on Medical Imaging, 8, 64-69. 